\title{
Faz değiştiren malzemeli duvarlarda sıcaklık dağılımının nümerik analizi
}

\section{Numerical analysis of temperature distribution in walls with phase change materials}

\author{
Meral ÖZEL ${ }^{1 *}$, Fethi Ahmet ÇAKMAK ${ }^{2}$, Nesrin İLGIN BEYAZIT ${ }^{3}$ \\ ${ }^{1}$ Fırat Üniversitesi, Mühendislik Fakültesi, Makine Mühendisliği Bölümü, Elazl̆̆, ORCID: 0000-0002-9516-4715 \\ ${ }^{2}$ Celal Bayar Üniversitesi, Soma Meslek Yüksekokulu, Makine ve Metal Teknolojileri Bölümü, Manisa, ORCID: 0000-0003-4575-5055 \\ 3Mardin Artuklu Üniversitesi, Mardin Meslek Yüksekokulu, Makine ve Metal Teknolojileri Bölümü, Mardin, ORCID: 0000-0003-4708- \\ 9615
}

\begin{tabular}{|c|c|}
\hline MAKALE BİLGILERİ & ÖZ \\
\hline Makale Geçmişi: & \\
\hline $\begin{array}{l}\text { Geliş } 15 \text { Ekim } 2021 \\
\text { Revizyon } 20 \text { Kasım } 2021 \\
\text { Kabul } 25 \text { Aralık } 2021 \\
\text { Online } 31 \text { Aralı } 2021\end{array}$ & $\begin{array}{l}\text { Bu çalışmada, bina dıș duvarlarında geleneksel 1sı yalıtım malzemesi yerine faz değiştiren malzeme } \\
\text { (FDM) kullanılarak duvar kalınlığı boyunca sıcaklık dağılımı ANSYS'de sayısal olarak araştırılmıştır. } \\
\text { Bu amaç için Elazığ ilinin kış iklim şartları göz önünde bulundurularak güney ve kuzeye bakan bir duvar } \\
\text { için beș farklı duvar modeli ele alınmıștır. Belirlen bu duvar modelleri için ilk önce duvarın kalınlığı } \\
\text { boyunca sıcaklık dağılımları hesaplanmıs ve daha sonra ise ısıl depolama kapasitelerini temsil eden faz }\end{array}$ \\
\hline $\begin{array}{l}\text { Faz değiştiren malzeme (FDM), } \\
\text { sicaklık dağılımı , ANSYS , Klş } \\
\text { şartlarl }\end{array}$ & $\begin{array}{l}\text { kayması ve sönüm oranları tespit edilmiştir. Sonuç olarak özellikle FDM'nin kullanılmasıyla duvar } \\
\text { içerisindeki sıcaklık dalgalanmalarının oldukça fazla sönümlenerek birbirine yakın sıcaklık değerlerinin } \\
\text { elde edildiği ve duvar içerisinde hemen hemen sabit kaldığı görülmüştür. Ayrıca maksimum faz kayması } \\
\text { ve minimum sönüm oranı açısından en iyi duvar yapısının FDM'nin dışta olduğu durumda elde edildiği } \\
\text { görülmüştür. }\end{array}$ \\
\hline
\end{tabular}

\begin{tabular}{ll}
\hline ARTICLE INFO & ABSTRACT \\
\cline { 2 - 2 } $\begin{array}{l}\text { Article history: } \\
\text { Received } 15 \text { Ekim } 2021\end{array}$ & $\begin{array}{l}\text { In this study, temperature distributions through thicknesses of walls were investigated numerically in } \\
\text { Received in revised form } 20\end{array}$ \\
$\begin{array}{l}\text { November } 2021 \\
\text { the building exterior walls. For this purpose, } 5 \text { different wall models were determined and analysed for } \\
\text { Accepted } 25 \text { December } 2021\end{array}$ & $\begin{array}{l}\text { winter climatic conditions by considering the climate data of Elazig province. For these determined wall } \\
\text { models, firstly the temperature distributions through the thickness of the wall were calculated, and then } \\
\text { the time lag and decrement factors representing the thermal storage capacities were determined. As a } \\
\text { Keywords: }\end{array}$ \\
$\begin{array}{l}\text { result, it is seen that temperature fluctuations in the wall was dampened considerably, especially with the } \\
\text { use of FDM, and temperature values close to each other are obtained and they remain almost constant } \\
\text { temperature distribution, } A N S Y S,\end{array}$ & $\begin{array}{l}\text { inside the wall. In addition, it was observed that the best wall structure in terms of maximum time lag } \\
\text { and minimum decrement factor was obtained when the FDM was outside. }\end{array}$
\end{tabular}

Doi: $10.24012 /$ dumf. 1051456

* Sorumlu Yazar 


\section{Giriș}

Günümüzde artan nüfus, şehirleşme, sanayileşme gibi durumlar enerji ihtiyacının artmasına neden olmaktadır. $\mathrm{Bu}$ ihtiyaçlardan dolayı alternatif enerji kaynakları bulma, eldeki enerjiyi depolama ve kullanılan kaynakların tasarrufu gibi konular üzerine daha çok yoğunlaşmaya başlanmıştır.

Dünya da enerji ihtiyacının \%78'i fosil yakıtlardan karşılanmaktadır. Fosil yakıtların gittikçe azalması gelecekte dünyanın enerji ihtiyaçlarının karşılanmasında zorluk çekileceğini göstermektedir. Ayrıca fosil yakıtların doğaya zarar verdiği de unutulmamalıdır. Tüm bu sebeplerden dolayı farklı enerji kaynakları araştırılmaya ve eldeki enerjinin daha verimli kullanılması için çalışmalar devam etmektedir [1].

Bir iși daha az enerji ile yaparak enerji tasarrufu yapılabilir. Binalarda kullanılan enerjinin büyük kısmı 1sıtma ve soğutma için kullanılmaktadır. $\mathrm{Bu}$ enerjinin verimli bir şekilde kullanılması 1sı yalıtımı ile sağlanabilir. $\mathrm{Bu}$ nedenle bina dıș duvarlarının yalıtılması gerekmektedir. Yapılarda uygun yalıtım malzemesinin kullanılmasıyla enerji kayıpları azalacağından ısıtma tesisinin kurulum maliyeti de azalacaktır. Kurulum maliyetleri ve 1sı kayıpları nedeniyle harcanan gereksiz enerji düşünüldüğünde yalıtımın ne kadar önemli olduğu anlaşılmış olur.

Binalarda 1sıtma ve soğutma uygulamalarında verimliliği arttırmak için faz değiştiren maddeler (FDM) kullanılmaktadır. Faz Değiştiren Maddeler (FDM) termal enerjiyi gizli ısı şeklinde depolayan maddelerdir ve FDM' nin bina uygulamalarında kullanımına tuz hidratlarının bir binada kullanılması ile 1970 yılında başlanmıştır [2].

Yapılan literatür araştırmasında FDM'ler ile ilgili sayısal ve deneysel olmak üzere birçok farklı uygulamayla karşılaşılmıştır. Bu konu ile ilgili olmak üzere yapılan çalışmalar incelendiğinde Çevik [3] Türkiye'nin güneydoğusunda duvar yapısının ısıl verimini artırmak ve isıl yalıtım alternatifi oluşturmak amacıyla iki özdeş test odası inşa etmiştir. Test odalarından birinin duvarı FDM doldurulmuş polikarbonat malzeme ile kaplanmıştır. Deneyler sonucunda FDM ile kaplanan duvarin kaplanmayana göre daha iyi 1sı yalıtım etkisi yaptığ 1 görülmüştür. Çırakman [4] faz değiştiren maddeyi güney duvarda kullanarak trombe bir duvar tasarlamış ve bu duvarın yıllık performansını deneysel olarak incelemiştir. Kandasamy vd [5] faz değiştiren malzeme uygulanmış bir kompozit duvarın yıl boyunca uygulanabilirliğini araştırarak yaz ve kış aylarında enerji tasarrufunun etkisi ile iç yüzey sıcaklıklarındaki dalgalanmaları incelemişler. Konuklu [6] Faz değiştiren malzemeleri mikrokapsülleyerek enerji depolama özelliğinin binalarda sağlayacağı enerji tasarrufunu incelemiştir. Sonuçlar uygulamanın; kış şartlarında 1sıtma için \%10-15 arası ve yaz şartlarında soğutma için \%5-10 arası verim sağladığını göstermiștir. Kurt [7] beton karıșımlarında faz değiştiren madde kullanarak dayanımı bozmadan isıl performansı artırmayı amaçlamıştır. Bu amaçla faz değişim sıcaklığ $23-26{ }^{\circ} \mathrm{C}$ olan $110 \mathrm{~J} / \mathrm{g}$ gizli ısıya sahip parafin kullanmıştır. FDM kullanılan betonun kullanılmayana göre daha yüksek bir isıl performansa sahip olduğunu göstermiştir. Mushtaq vd [8] yalıtım olarak faz değiştiren malzeme kullanımını deneysel olarak incelemişler. Bu çalışma için standart ve FDM kullanılan iki ayrı oda inşa ederek Faz değiștiren malzeme olarak $44{ }^{\circ} \mathrm{C}$ erime sıcaklığına sahip olan parafin kullanmışlar. Quanying vd [9] duvarlara farklı şekilde yerleştirilmiş faz değiștiren malzemelerin termal özelliklerini incelemek için parafin kullanılmıştır. Faz değiştiren malzeme kullanılan duvar ile klasik beton duvar karşılaştırılmıştır. Sonuçlara göre doğrudan karıştırma yöntemine nazaran laminasyon enterpolasyon yöntemi ile hazırlanan duvarda ki enerji tasarrufu daha iyi olmuştur. $\mathrm{Bu}$ yöntem ile hazırlanan faz değişim malzemesinin gizli 1s1 depolama kapasitesi ve daha belirgin enerji tasarrufu sağladığı görülmüştür. Laminasyon yönteminin karmaşık ve uygulanabilirliğinin zorluğu vurgulanmıştır. Örengül [10] yapıların FDM içeren tavanın isı yalıtımına olan etkisini deneysel olarak araştırmıştır. Bu çerçevede iki özdeș yapı inşa etmiştir. Yapıların birinin tavanı FDM doldurulmuş delikli tuğlayla örülmüştür. Sonuç olarak FDM kullanılan tavanın diğerine göre daha iyi bir günlük 1S1 yalıtımı sağladığ1 saptanmıştır. Tokuç [11] faz değiştiren malzemelerin isıl depolama amacıyla yeni nesil bina malzemesi olarak kullanımının enerji kazanımı sağlayacak bir yöntem geliştirmesini amaçlamıştır. Kullanılan yöntem ile elde edilen sonuçlarda FDM ile geliştirilen yapı bileşenlerinin binalarda kullanımına yardımcı olabilecek veriler tartışılmış ve sonraki çalışmalar için önerilerde bulunulmuştur.

Yukarıda görüldüğü gibi literatürde FDM kullanımıyla ilgili çalışmaların çoğunun deneysel olduğu ve enerjinin depolanarak ortamın ısıtılması amaçlandığı görülmektedir. $\mathrm{Bu}$ çalışmada ise bina dış duvarlarında yalıtım yerine FDM kullanımının etkisini araştırmak için beş farklı duvar yapısı ele alınarak ve kış şartları göz önünde bulundurularak duvar kalınlığı boyunca sicaklık dağılımları, faz kayması ve sönüm oranları sayısal olarak hesaplanmıştır. Hesaplamalar güney ve kuzey yönleri için ANSYS Fluent programı ile gerçekleştirilmiştir. Gerçek şartlara yakın bir analiz gerçekleştirmek için bina dış yüzeyinin gün boyunca değişen güneş 1 şınımı ve dış ortam sıcaklıklarına maruz kaldığı göz önünde bulundurulmuştur.

\section{Matematiksel Metot}

FDM içeren katmanlı duvar Şekil 1'de gösterilmiştir. Duvarın iç ve dış yüzeylerinde $2 \mathrm{~cm}$ kalınlığında sıva bulunmakta olup duvar $2 \mathrm{~cm}$ FDM ve toplam $20 \mathrm{~cm}$ kalınlığında tuğladan oluşmaktadır. Tuğla ve sıva katmanları için fiziki özelliklerin homojen olduğu ve sıcaklıkla değişmediği kabul edilmiştir. Duvar katmanları arasındaki temas direnci dikkate alınmamıştır. 


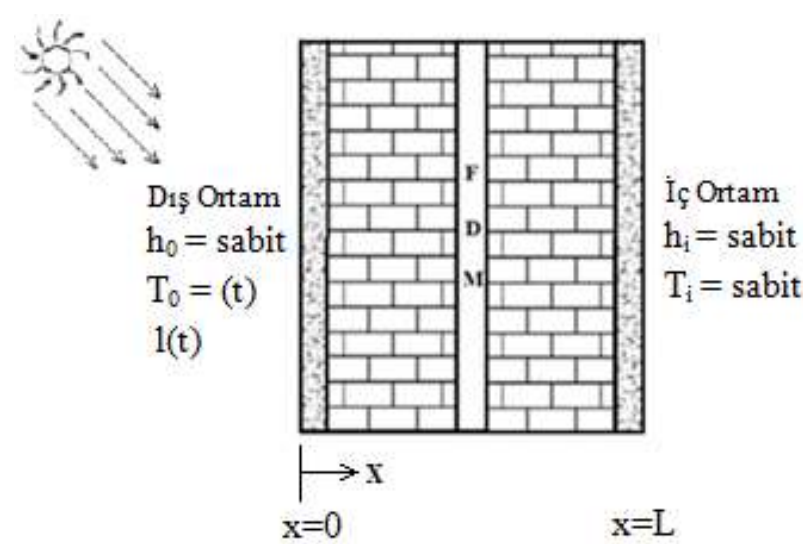

Şekil 1. FDM ile yalıtılmış duvar modeli

Ortamın 1sı kazanç ve kaybının hesaplanabilmesi için duvarın iç yüzey sıcaklığının bilinmesi gerekir. Katmanlı düzlem duvarda sıcaklık dağılımı aşağıda verilen geçici rejimde bir boyutlu 1sı iletiminin uygun sınır şartları kullanılarak çözülmesi ile elde edilmiştir.

$$
\frac{\partial T}{\partial t}=\alpha \frac{\partial^{2} T}{\partial x^{2}}
$$

Burada $\alpha=k / \rho c_{p}$ olup k duvar malzemesinin 1s1 iletkenliği $\rho$ yoğunluk ve $c_{\mathrm{p}}$ isı kapasitesidir. İç ve dış yüzeydeki sınır şartları aşă̆ıdaki gibidir.

$\mathrm{x}=\mathrm{L}$ için

$-k\left(\frac{\partial T}{\partial x}\right)_{x=L}=h_{i}\left(T_{x=L}-T_{i}\right)$

$\mathrm{x}=0$ için

$-k\left(\frac{\partial T}{\partial x}\right)_{x=0}=h_{0}\left(T_{e}-T_{x=0}\right)$

Burada $T_{e}$ eşdeğer çevre sıcaklığı olup diş ortam sıcaklı̆̆ $\mathrm{T}_{0}$, güneş ışınımı şiddeti I, duvarın güneş ışınımı emiciliği

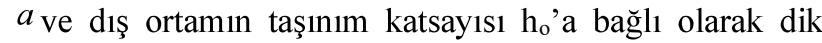
duvar yüzeyleri için aşağıdaki şekilde hesaplanmaktadır.

$$
T_{e}=T_{0}+\frac{a I}{h_{0}}
$$

FDM 'nin katı-sıvı ara yüzeyi için aşağıdaki bağıntı kullanılmıştır [12].

$$
k_{k} \frac{\partial T_{k}}{\partial x}-k_{s} \frac{\partial T_{s}}{\partial x}=\rho L \frac{\partial S_{(t)}}{\partial t}
$$

\section{Yapıların Faz Kayması ve Sönüm Oranları}

Sürekli değişen iklim koşullarının etkisinde kalan dış duvarlar, ısıtma/soğutma yükünün azaltılmasında ssıl kütle olarak rol oynarlar. Duvarı oluşturan katmanların konumu ve termofiziksel özellikleri, binanın ısıl performansının belirlenmesinde önemli parametrelerdendir. Bu bağlamda faz kayması ve sönüm oranı binanın ısıl enerji depolamasında belirleyici rol oynamaktadır. Günlük sıcaklık değişimlerinin yüksek olduğu bölgelerde, faz kayması ve sönüm oranlarının belirlenmesi, enerji etkin bina tasarımlarında ısıtma yükünün azaltılması için önemlidir.

Şekil 2'de görüldüğü gibi sinüzoidal sıcaklık dalgası, dış yüzeyden iç yüzeye ulaşıncaya kadar geçen zaman, yani eşdeğer dış sıcaklığın en yüksek olduğu zaman ile iç yüzey sıcaklığının en yüksek olduğu zaman arasındaki fark, faz kayması olarak adlandırılır. $\mathrm{Bu}$ işlem süresince onun genliğinde meydana gelen küçülme miktarı, başka bir ifadeyle iç yüzey sıcaklı̆̆ının genliğinin eşdeğer çevre sıcaklığının genliğine oranı da, sönüm oranı olarak adlandırılmaktadır. Bu iki özellik, yapıların 1sı depolama kapasitelerini hesaplamak için çok önemli bir kriterdir. Faz kayması matematiksel olarak aşağıdaki gibi ifade ediliştir [13].

$\phi=t_{T d i(\max )}-t_{T e(\max )}$

Burada $t_{T d i(\max )}$ iç yüzey sıcaklığının maksimum olduğu zaman, $\mathrm{t}_{\mathrm{Te}(\max )}$ ise eşdeğer dış sıcaklığın en yüksek değerine ulaştı̆ğ zamanı belirtmektedir. Sönüm oranı ise matematiksel olarak genliklerin birbirine oranı olup

$f=\frac{T_{d i}(\max )-T_{d i}(\min )}{T_{e}(\max )-T_{e}(\min )}$

şeklinde ifade edilir [13]. 


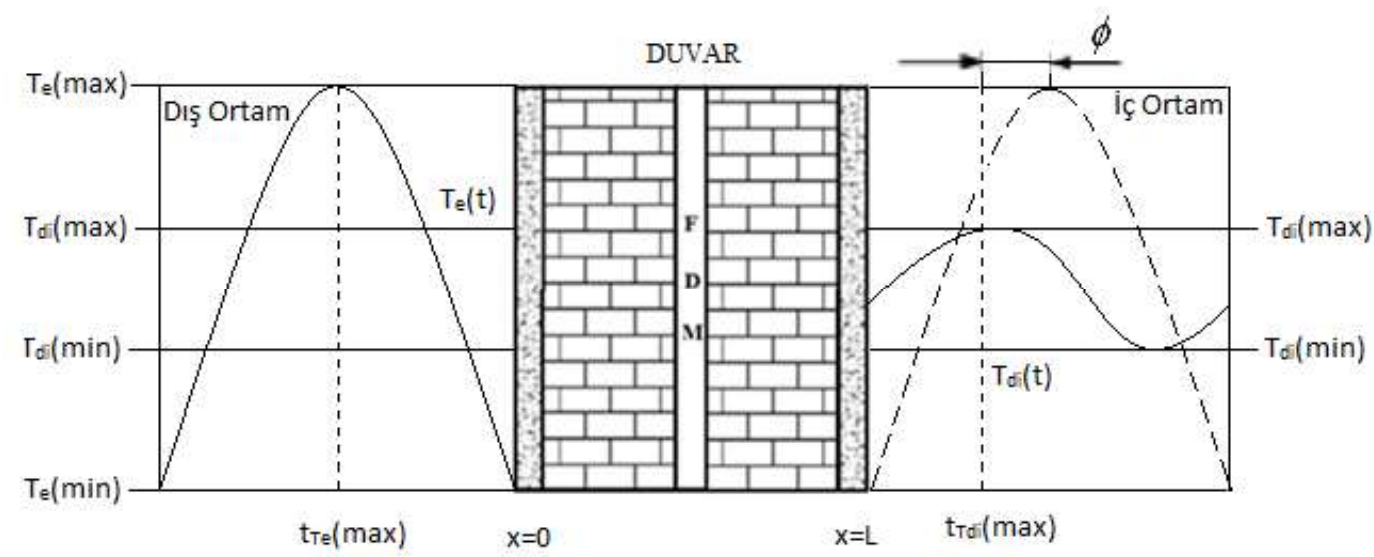

Şekil 2. Faz kayması ve sönüm oranı şematik gösterimi [13].

\section{Sayısal Yöntem}

$\mathrm{Bu}$ çalışmada, bina dış duvarlarında yalıtım yerine FDM kullanılarak kış şartları için duvar kalınlığı boyunca sıcaklık dağılımı sayısal olarak hesaplanmıştır. Analizler güney ve kuzey yönleri için ANSYS Fluent programı ile iki boyutlu ve zamana bağlı olarak gerçekleştirilmiştir. Program aşamaları aşağıda sıralanmıştır;

1) Geometri: $\mathrm{Bu}$ aşamada yalıtımlı ve yalıtımsız duvar modellerinin çizimi yapılmıştır. Yalıtımsız ve yalıtımın dışta, içte ve ortada olduğu durumlar için beş farklı model tasarlanmıştır.

2) Ăg yapısı (mesh): ANSYS programında analizlerin düzgün bir şekilde yapilabilmesi için duvar modelleri üzerine ağ yapılarının atanması gerekmektedir. A $\breve{g}$ yapısı analizin doğru bir şekilde çözülmesindeki en önemli parametrelerden birisidir. Bu çalışmada kare şeklinde ağ yapısı kullanılmıştır. Yalıtımsız duvar modelinde düğüm sayısı 4067, eleman sayısı 3808 olarak belirlenmiştir. Yalıtımlı duvar modellerinde ise düğüm sayısı 4014 eleman sayısı 3696 olarak belirlenmiştir. Yalıtımsız ve yalıtımın dışta olduğu duvar modellerine ait ağ yapısı Şekil 3' de gösterilmiştir.

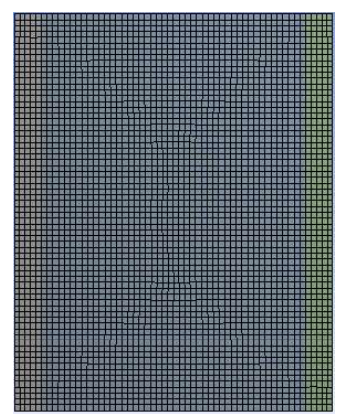

(a)

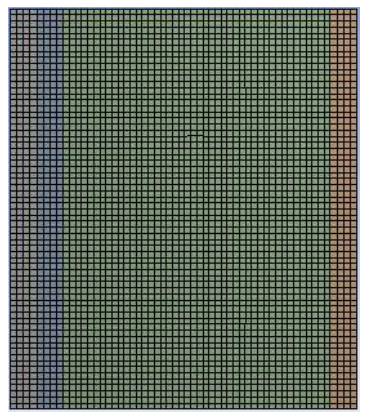

(b)
Şekil 3. Ăg yapıları (mesh): (a) Yalıtımsız duvar modeli (b) Yalıtımın dışta olduğu duvar modeli

3) Çözüm adımları: Geometri ve ağ yapısı belirlenen modeller için malzeme özellikleri, sınır şartları, iterasyon ve yakınsama değerleri ile çözüm metodları bu aşamada programa girilmiştir.

Analizlerde kullanılan FDM, sıva, tuğla ve camyünü malzemelerinin tablolarda belirtilen özellikleri girilmiştir.

Sınır şartı olarak iç ortamda kış şartlarında $18{ }^{\circ} \mathrm{C}$ ve taşınım katsayısı sabit $8 \mathrm{w} / \mathrm{m}^{2} \mathrm{~K}$, dış ortamda ise değişken sıcaklık şartı ile taşınım katsayısı $23 \mathrm{w} / \mathrm{m}^{2} \mathrm{~K}$ olarak belirlenmiştir. Dış yüzey 24 saat boyunca değişen güneş 1şınımı ve dış ortam sıcaklığına maruz kaldığ1 için 24 farklı eşdeğer sıcaklık değeri hesaplanmıştır. Değişken sıcaklık şartının programa uygulanabilmesi için User Defined Function (UDF) da kullanılmak için bir C kodu oluşturulmuştur. Bu kod sayesinde her bir saatin sıcaklığ 1 farklı olacak şekilde ardıl günlerde tekrarlı olacak şekilde yazılmıştır. Bu sayede birkaç gün üst üste her bir saatin değeri kendi zamanı geldiğinde sınır şartı olarak otomatik uygulanmıştır.

Çözüm metodu olarak basınca dayalı SIMPLE seçeneği kullanılmıştır. Sistem başlangıç sıcaklığı olarak $18{ }^{\circ} \mathrm{C}$ olarak belirlenmiştir. Yakınsama değeri olarak continuity $=1 \mathrm{e}-03, \mathrm{x}-\mathrm{y}$ velocity $=1 \mathrm{e}-03$ ve energy $=1 \mathrm{e}-06$ olarak girilmiştir. İterasyon sayısı 1000 olup her 3600 saniyede bir tüm değerler kaydedilecek şekilde ayarlanmıştır.

\section{Duvar Modellerinin Tanıtılması}

$\mathrm{Bu}$ çalışmanın ana amacı yalıtım yerine FDM'nin kullanılması ve mevcut yalıtım ile kıyaslanmasıdır. Daha önce çok katmanlı duvarların kalınlıkları boyunca sıcaklık dağılımları ANSYS' de analiz edilmiş ve 3 farklı yalıtılmış duvar yapısı ele alınarak sıcaklık dağılımları yaz ve kış şartları için hesaplanmıştır [14]. Ancak bu çalışmada ise FDM' nin duvar yapısında kullanımı ele alınmış ve mevcut yalıtım malzemesi ile kıyaslanmıştır.

Bu amaçla Şekil 4'de gösterilen beş farklı duvar modeli belirlenerek ilk önce duvarın kalınlığı boyunca sıcaklık dağılımları belirlenmiş ve daha sonra ise ısıl depolama kapasitelerini temsil eden faz kayması ve sönüm oranları belirlenmiştir. Tüm duvar modelleri, içte ve dişta $2 \mathrm{~cm}$ kalınlığında sıva ve toplam $20 \mathrm{~cm}$ kalınlığında tuğladan 
oluşmuştur. Camyünü yalıtım malzemesi ve FDM'nin kalınlıkları ise $2 \mathrm{~cm}$ olarak belirlenmiştir.

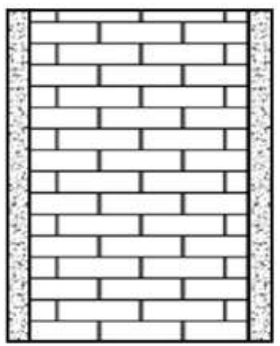

(a)

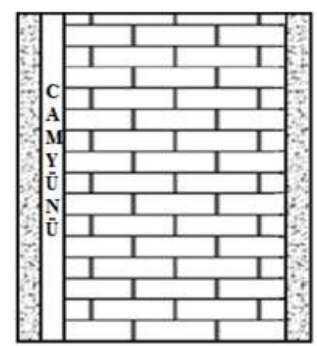

(b)

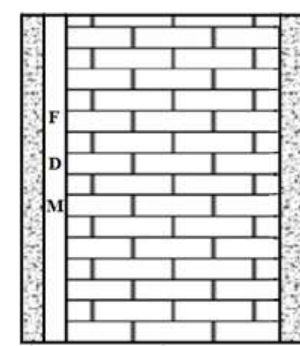

(c)

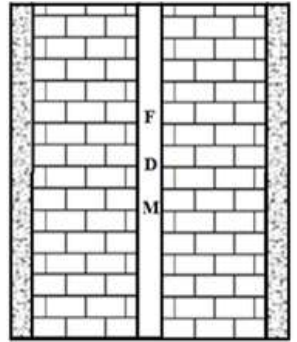

(d)

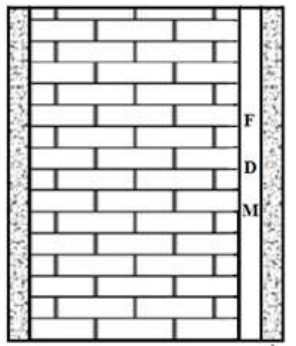

(e)

Şekil 4. Duvar modelleri: (a) Yalıtımsız duvar modeli (b) Camyününün dışta olduğu duvar modeli (c) FDM'nin dışta olduğu duvar modeli (d) FDM'nin ortada olduğu duvar modeli (e) FDM'nin içte olduğu duvar modeli

Tasarlanan duvar modellerinin iç ve dış ortamları belirli sınır şartlarına maruzdur. Kış şartlarında iç ortam sıcaklığının sabit $18 \mathrm{oC}$ olduğu ve taşınım katsayısının 8 $\mathrm{w} / \mathrm{m}^{2} \mathrm{~K}$ olduğu kabul edilmektedir. Dıș ortamda ise taşınım katsayısı sabit $23 \mathrm{w} / \mathrm{m}^{2} \mathrm{~K}$ olarak kabul edilip sıcaklığın değişken olduğu ve diş ortamın güneş ışınımına maruz kaldığı göz önünde bulundurularak eşdeğer sıcaklık değerleri belirlenmiştir. Bu sıcaklıklar 24 adet olup her bir saat için farklı değere sahiptirler. Farklı eşdeğer sıcaklıkları bir kod yardımı ile programa tanımlanıp analizlerde kullanılmıştır. Bu sayede gerçek şartlara yakın bir analiz yapılmıştır.

Dış ortamdaki eş değer çevre sıcaklıkları güney ve kuzey yönler ayrı olacak şekilde sırasıyla Tablo 1 ve 2'de gösterilmiştir.

Tablo 1. Güneye bakan duvarın eșdeğer çevre sıcaklıkları

\begin{tabular}{|l|c|c|c|c|c|c|c|c|c|c|c|c|}
\hline $\mathbf{t}$ (saat) & $\mathbf{1}$ & $\mathbf{2}$ & $\mathbf{3}$ & $\mathbf{4}$ & $\mathbf{5}$ & $\mathbf{6}$ & $\mathbf{7}$ & $\mathbf{8}$ & $\mathbf{9}$ & $\mathbf{1 0}$ & $\mathbf{1 1}$ & $\mathbf{1 2}$ \\
\hline $\mathbf{T}_{\text {eș }} \mathbf{}^{\mathbf{}} \mathbf{C}$ ) & $-3,10$ & $-3,45$ & $-3,55$ & $-3,56$ & $-3,80$ & -4 & $-4,1$ & $-1,63$ & 4,20 & 7,96 & 10,27 & 11,17 \\
\hline $\mathbf{t}$ (saat) & $\mathbf{1 3}$ & $\mathbf{1 4}$ & $\mathbf{1 5}$ & $\mathbf{1 6}$ & $\mathbf{1 7}$ & $\mathbf{1 8}$ & $\mathbf{1 9}$ & $\mathbf{2 0}$ & $\mathbf{2 1}$ & $\mathbf{2 2}$ & $\mathbf{2 3}$ & $\mathbf{2 4}$ \\
\hline $\mathbf{T}_{\text {eș }}\left({ }^{\mathbf{}} \mathbf{C}\right)$ & 10,97 & 10,06 & 7,10 & 2,87 & $-0,20$ & $-1,2$ & $-1,9$ & $-2,16$ & $-2,15$ & $-2,34$ & $-2,69$ & $-2,81$ \\
\hline
\end{tabular}

Tablo 2. Kuzeye bakan duvarın eșdeğer çevre sıcaklıkları

\begin{tabular}{|l|c|c|c|c|c|c|c|c|c|c|c|c|}
\hline $\mathbf{t}$ (saat) & $\mathbf{1}$ & $\mathbf{2}$ & $\mathbf{3}$ & $\mathbf{4}$ & $\mathbf{5}$ & $\mathbf{6}$ & $\mathbf{7}$ & $\mathbf{8}$ & $\mathbf{9}$ & $\mathbf{1 0}$ & $\mathbf{1 1}$ & $\mathbf{1 2}$ \\
\hline $\mathbf{T}_{\text {es }}\left({ }^{\circ} \mathbf{C}\right)$ & $-3,10$ & $-3,44$ & $-3,55$ & $-3,569$ & $-3,80$ & $-4,00$ & $-4,10$ & $-3,08$ & $-0,19$ & 1,49 & 2,88 & 3,45 \\
\hline $\mathbf{t}$ (saat) & $\mathbf{1 3}$ & $\mathbf{1 4}$ & $\mathbf{1 5}$ & $\mathbf{1 6}$ & $\mathbf{1 7}$ & $\mathbf{1 8}$ & $\mathbf{1 9}$ & $\mathbf{2 0}$ & $\mathbf{2 1}$ & $\mathbf{2 2}$ & $\mathbf{2 3}$ & $\mathbf{2 4}$ \\
\hline $\mathbf{T}_{\text {eș }}\left({ }^{\circ} \mathbf{C}\right)$ & 3,58 & 3,59 & 2,70 & 1,41 & $-0,20$ & $-1,20$ & $-1,90$ & $-2,16$ & $-2,15$ & $-2,34$ & $-2,69$ & $-2,81$ \\
\hline
\end{tabular}

\section{Analizlerde Kullanılan Malzemelerin Termofiziksel Özellikleri}

$\mathrm{Bu}$ çalışmada FDM olarak $16-18^{\circ} \mathrm{C}$ aralığında erime özelliğine sahip kaprilik asit kullanılmıştır. FDM' nin ve duvar yapısında kullanılan diğer elemanların termofiziksel özellikleri ise sırasıyla Tablo 3 ve 4' de verilmiștir.
Tablo 3. Kaprilik asitin termofiziksel özellikleri [15]

\begin{tabular}{|l|c|}
\hline Erime aralığı & $16-18^{\circ} \mathrm{C}$ \\
\hline Gizli Isı & $148,5 \mathrm{~kJ} / \mathrm{kg}$ \\
\hline Katı halde ısı depolama kapasitesi & $981 \mathrm{~kJ} / \mathrm{kgK}$ \\
\hline Sıvı halde 1sı depolama kapasitesi & $901 \mathrm{~kJ} / \mathrm{kgK}$ \\
\hline Katı halde termal iletkenlik & $0,23 \mathrm{~W} / \mathrm{mK}$ \\
\hline Sıvı halde termal iletkenlik & $0,149 \mathrm{~W} / \mathrm{mK}$ \\
\hline
\end{tabular}




\begin{tabular}{|l|c|} 
Katı halde sabit yoğunluk & $2110 \mathrm{~kg} / \mathrm{m}^{3}$ \\
\hline Sıvı halde sabit yoğunluk & $1950 \mathrm{~kg} / \mathrm{m}^{3}$ \\
\hline
\end{tabular}

Tablo 4. Sıva ve tuğlanın termofiziksel özellikleri [16]

\begin{tabular}{|c|c|c|c|}
\hline & $\boldsymbol{\rho}\left(\mathbf{k g} / \mathbf{m}^{\mathbf{3}}\right)$ & $\mathbf{c}_{\mathbf{p}}(\mathbf{J} / \mathbf{k g K})$ & $\mathbf{k} \mathbf{( W / m K})$ \\
\hline Tuğla & 1800 & 840 & 0,62 \\
\hline Sıva & 1865 & 840 & 0,72 \\
\hline Cam yünü & 105 & 795 & 0.036 \\
\hline
\end{tabular}

\section{Sonuçlar ve tartışma}

$\mathrm{Bu}$ çalışmanın ana amacı yalıtım yerine FDM'nin kullanılması ve mevcut yalıtım ile kıyaslanmasıdır. Bu amaçla belirlenen duvar modelleri için ilk önce duvarın kalınlığı boyunca sıcaklık dağılımları hesaplanmış ve daha sonra ise 1sıl depolama kapasitelerini temsil eden faz kayması ve sönüm oranları tespit edilmiştir.

FDM'nin erime gerçekleşen bölgelerini görebilmek için aşağıdaki sıcaklık dağılımları çizilmiştir. Şekil 5 ve 6'da sırasıyla FDM ile dıştan yalıtımlı ve yalıtımsız duvar modellerine ait belirli zamanlardaki sıcaklık dağılımları verilmiştir. FDM'li duvar modellerine ait sicaklık değişimlerinde erime meydana geldiği zaman sıcaklıktaki değişim şekillerde görülmektedir. Bu değişimler düzenli bir şekilde ilerleyen sıcaklık dağılımının erimenin başlamasıyla farklı bir hal almıştır. Yalıtımsız ve camyünü ile yalıtılmış duvar modellerinin sıcaklık dağılımlarında erime ve katılaşma olmadığından böyle bir durum gözlemlenmemiştir.
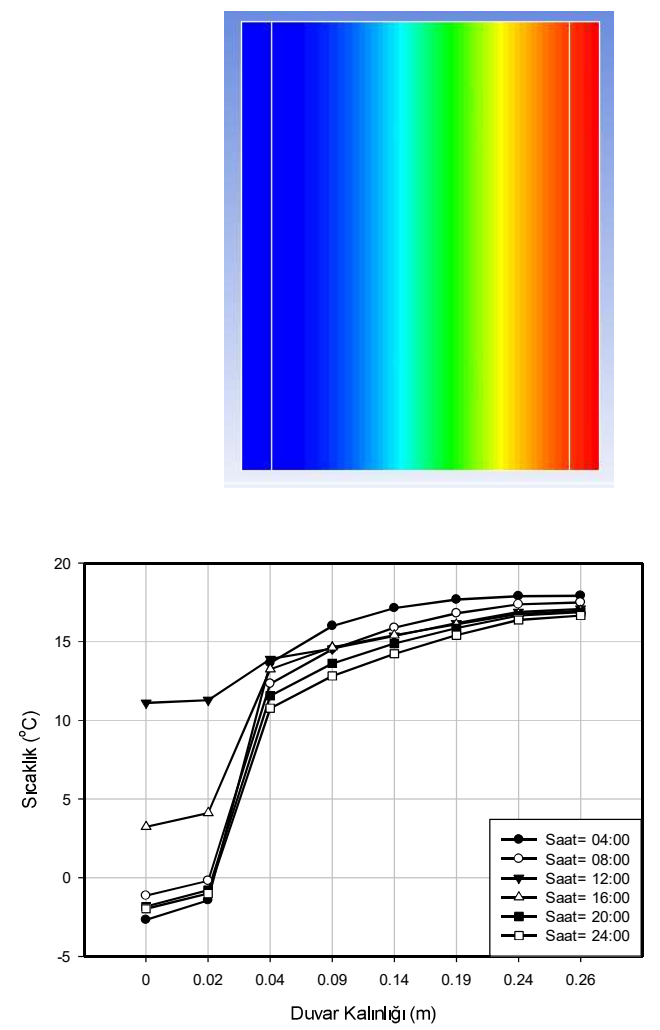

a) Camyünü
Şekil 5. Yalıtımsız duvar modeline ait sıcaklık dağılımı

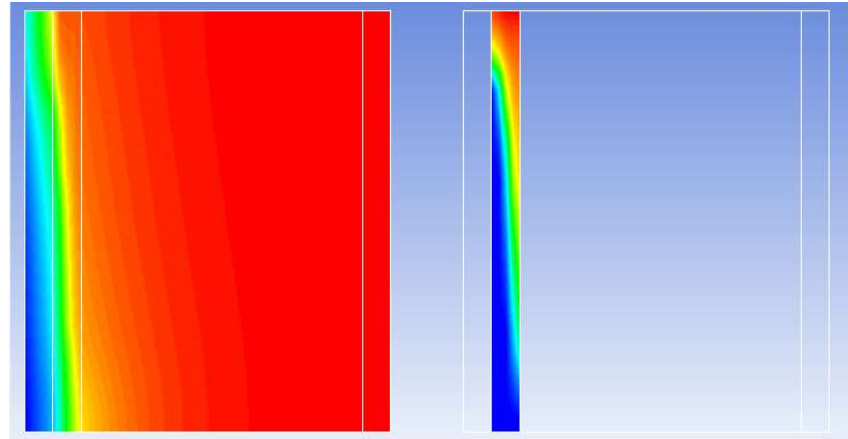

Şekil 6. FDM ile dıştan yalıtılmış duvar modeline ait sıcaklık dağılımı ve erime gerçekleşen bölge

Elâzığ'ın kış iklim şartları dikkate alınarak güneye bakan beş farklı duvar modeli için zamana bağlı sıcaklık değişimleri Şekil 7-9' da verilmiştir.

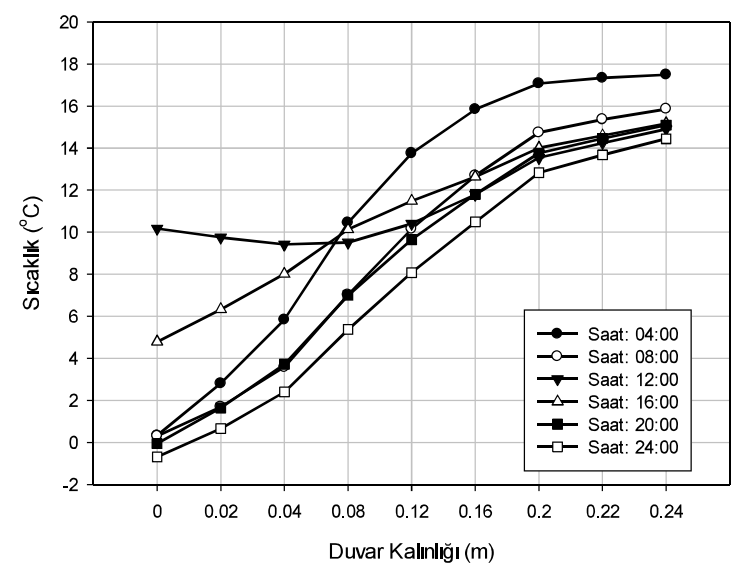

Şekil 7. Yalıtımsız duvar modeli için duvar kalınlığ boyunca zamana bağlı sicaklık değişimi

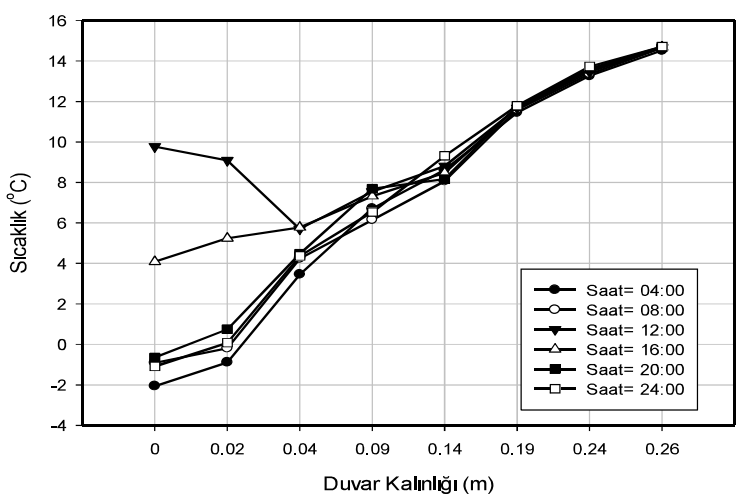

b) FDM dişta 
Şekil 8. Camyünü ve FDM' nin dışta olduğu duvar modelleri için duvar kalınlığı boyunca zamana bağlı sıcaklık değişimleri

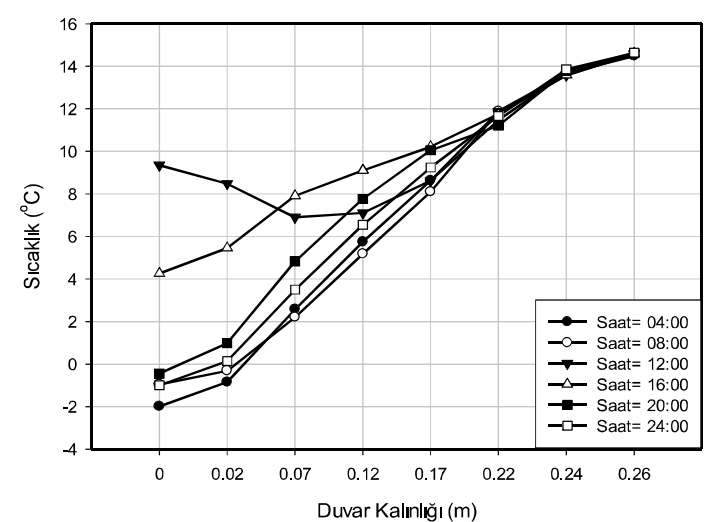

a) FDM içte

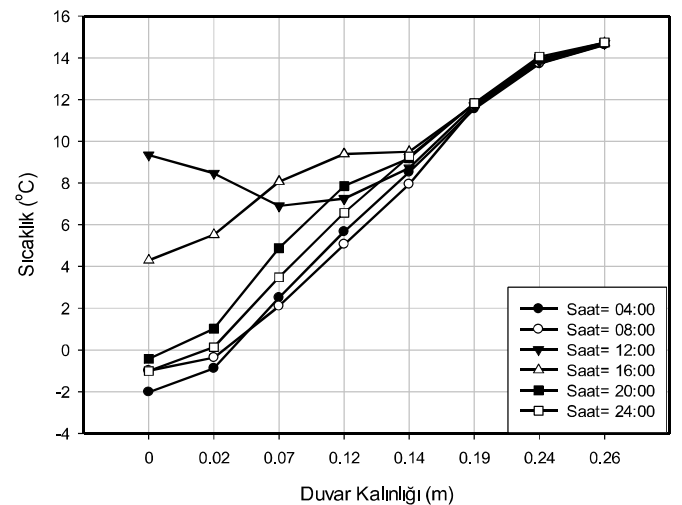

b) FDM ortada

Şekil 9. FDM'nin içte ve ortada olduğu duvar modelleri için duvar kalınlı̆̆ı boyunca zamana bă̆lı sıcaklık değişimleri

Yalıtımsız duvar hariç diğer tüm duvar modellerinde duvar kalınlığı $26 \mathrm{~cm}$ 'dir ve grafiklerde 4'er saatlik aralıklarla duvar kalınlığı boyunca sıcaklık dağılımları görülmektedir. Yalıtımsız duvarda, duvarın kalınlığı boyunca sıcaklık dalgalanmalarının oldukça fazla olduğu görülmektedir. Grafiklere bakıldığında duvarın dış yüzeyinde minimum sicaklık saat 4'te elde edilirken maksimum sıcaklık saat 12 'de elde edilmektedir. Bunun nedeni güneye bakan duvarda maksimum güneş ışınımının öğlen saatinde elde edilmesinden kaynaklanmaktadır. Ayrıca duvarın dış yüzeyinde yaklaşık olarak $-2^{\circ} \mathrm{C}$ ile $10^{\circ} \mathrm{C}$ arasında sıcaklık dalgalanması olduğu ve bu dalgalanmaların duvarın dış yüzeyinden iç yüzeyine doğru azaldığı görülmektedir. Özellikle bu azalma yalıtım malzemesi ve FDM'nin uygulandığ1 yerlerde daha belirgin olmuştur. Burada amaç duvara yalıtım veya FDM uygulanarak dış sıcaklık dalgalanmalarını sönümleyip iç yüzey yayılımını en aza indirmektir.

Duvara camyünü yalıtım uygulandığında yalıtım tabakasının etkisiyle sıcaklık dalgalanmalarının oldukça azaldığı görülmektedir. Ancak duvara aynı kalınlıkta FDM yerleştirilerek bu azalmanın daha fazla olduğu görülmüştür. Özellikle FDM'nin kullanılmasıyla duvar içerisindeki sıcaklık salınımları oldukça fazla sönümlenerek birbirine yakın sıcaklık değerleri elde edilmiş ve duvar içerisinde hemen hemen sabit kalmıştır. FDM'nin dişta olması durumu içte ve ortada olmasına göre en az sıcaklık dalgalanmalarının olduğu görülmüştür. Yani FDM'nin duvarın dışına yerleştirilmesi duvar kalınlığı boyunca sıcaklık dalgalanmalarını en aza indirdiği tespit edilmiştir.

Çok katmanlı duvar yapısında katmanların yeri ve kalınlığının faz kayması ve sönüm oranı üzerine etkisi vardır. Duvarın 1sı depolama kapasitesinin yüksek olması, faz kaymasını arttırırken sönüm oranını ise küçültür. Faz kaymasının büyük sönüm oranının küçük değerlerde olması, iç mekan konforu açısından istenen bir durumdur. Tablo 5'de güney ve kuzeye bakan tüm duvar modellerine ait faz kayması ve sönüm oranı değerleri yer almaktadır. Tablodan da görüldüğü üzere FDM ile yalıtılmış duvar modellerine ait değerlerin yalıtımsız ve camyünü ile yalıtılmış modellere göre 1sı depolama kapasitesi açısından daha iyi olduğu görülmektedir. Ayrıca maksimum faz kayması ve minimum sönüm oranı açısından en iyi duvar yapısının FDM'nin dışta olduğu durumda elde edilmiştir.

Tablo 5. Kış şartlarında güney ve kuzeye bakan tüm duvar modellerine ait faz kayması ve sönüm oranı değerleri

\begin{tabular}{|l|c|c|c|c|}
\hline \multirow{2}{*}{ Duvar yapısı } & \multicolumn{2}{|c|}{ Güney } & \multicolumn{2}{c|}{ Kuzey } \\
\cline { 2 - 5 } & $\begin{array}{c}\text { Faz } \\
\text { Kayması }\end{array}$ & $\begin{array}{c}\text { Sönüm } \\
\text { Oranı }\end{array}$ & $\begin{array}{c}\text { Faz } \\
\text { Kaymas }\end{array}$ & $\begin{array}{c}\text { Sönüm } \\
\text { Oran1 }\end{array}$ \\
\hline Yalıtımsız & 5 & 0,309 & 5 & 0,291 \\
\hline Camyünü & 6 & 0,12 & 6 & 0,211 \\
\hline FDM Dışta & 9 & 0,043 & 8 & 0,064 \\
\hline FDM İçte & 8 & 0,045 & 8 & 0,066 \\
\hline FDM Ortada & 8 & 0,048 & 8 & 0,069 \\
\hline
\end{tabular}

\section{Sonuç}

$\mathrm{Bu}$ çalışmada Elazığ iklim şartlarında yalıtım malzemesi olarak faz değiştiren malzeme kullanılarak kış şartları için sıcaklık dağılımları, faz kayması ve sönüm oranları FDM' nin farklı konumları için ANSYS'de sayısal olarak araştırılmıştır. Elde edilen sonuçlar Cam yünü yalıtım malzemeli duvar ile kıyaslanmıştır.

Seçilen FDM'nin uygun bir erime ve katılaşma sıcaklığ aralığında olması gerekmektedir. Bu yüzden bu çalışmada 
faz değiștiren malzeme olarak $16-18{ }^{\circ} \mathrm{C}$ aralığında eriyen kaprilik asit kullanılmıştır.

Sonuç olarak, yaz ve kış şartlarında duvara FDM uygulanarak dış sıcaklık dalgalanmaları sönümlenip iç yüzeye yayılımının en aza indirilmesi sağlanmıştır. Ayrıca duvara FDM uygulanarak duvarın 1sı depolama kapasitesinin (maksimum faz kayması ve minimum sönüm oranı) arttığ1 da görülmüştür.

\section{Kaynaklar}

[1] O.M. Yılmaz, "Yeraltı termal enerji depolamada kullanılan farklı dolgu maddelerinin termal özelliklerinin araştırılması", Doktora Tezi, Ç.Ü. Fen Bilimleri Enstitüsü, Adana. 2005.

[2] Y. Konuklu, H.Ö. Paksoy, "Faz değiştiren maddeler ile binalarda enerji verimliliği”, X. Ulusal Tesisat Mühendisliği Kongresi - 13/16 Nisan 2011/İzmir, 919-930.

[3] M. Çevik, "Faz değiştiren maddelerle duvar 1sıl yalıtımının deneysel olarak araştırılması", Yüksek Lisans Tezi, Fırat Üniversitesi Fen Bilimleri Enstitüsü, Elazığ, 2012.

[4] A. Çırakman, "Faz değiștiren madde içeren bina güney duvarının deneysel olarak incelenmesi", Doktora Tezi, Atatürk Üniversitesi Fen Bilimleri Enstitüsü, Erzurum, 2010.

[5] R. Kandasamy, Q.X. Wang, and S.A. Mujumdar, "Application of phase change materials in thermal management of electronics," Applied Thermal Engineering,27, 2822-2832. 2007.

[6] Y. Konuklu,"Mikrokapsüllenmiş faz değiştiren maddelerde termal enerji depolama ile binalarda enerji tasarrufu", Doktora tezi, Ç.Ü. Fen Bilimleri Enstitüsü, Adana. 2008.
[7] S. Kurt, "Yeni nesil bina malzemeleri için faz değiştiren madde geliştirilmesi”, Yüksek Lisans Tezi, Çukurova Üniversitesi Fen Bilimleri Enstitüsü, Adana.2012.

[8] I. Hasan, Mushtaq, O. Hadi, Basher, Ahmed, Shdhan, "Experimental investigation of phase change materials for insulation of residental buildings," Sustainable Cities and Society 36 (2018) 42-58. 2018.

[9] Y. Quanying, H. Ran and L. Lisha, "Experimental study on the thermal properties of the phase change material wall formed by different methods," Solar Energy 86 (2012) 3099-3102. 2012.

[10] F. Örengül, "Gizli 1sı depolamalı tavan 1sıl yalıtımının neysel olarak araștırılması", Yüksek Lisans Tezi, Furat Üniversitesi Fen Bilimleri Enstitüsü, Elazığ. 2010.

[11] Tokuç A., "Faz değişim malzemelerinin 1sıl enerji depolama amaciyla yapı elemanı üretiminde kullanılması", Doktora Tezi, Dokuz Eylül Üniversitesi Fen Bilimleri Enstitüsü, İzmir. 2013.

[12] A. Daloğlu, "Isı Yalıtımında Faz Değiştiren Malzeme Kullanımı," X. Ulusal Tesisat Mühendisliği Kongresi, İzmir. 2011.

[13] M. Özel, "Duvar Yüzeylerinde Periyodik Sıcaklık Değişimi Olan Binalarda Isı Kazanç ve Kayıpların Minumum Yapacak Yöntemlerin Araştırılması", Doktora Tezi, Fırat Üniversitesi Fen Bilimleri Enstitüsü, Elazı̆̆. 2003.

[14] M. Özel, N. İlgin, "Periyodik Sınır Şartlarına Maruz Kalan Çok Katmanlı Duvarlarda Sıcaklık Dağılımının ANSYS' de Analizi," Tesisat dergisi, 27-32. 2012.

[15] M. Okcu, "Faz değiştiren maddelerde erime ve katılaşma sürecinin sayısal olarak incelenmesi", Yüksek Lisans Tezi, Frrat Üniversitesi Fen Bilimleri Enstitüsü, Elazığ. 2011.

[16] Cengel, Yunus A., and Afshin J. Ghajar. "Heat and mass transfer." A practical approach 2007 